\title{
Gender differences in solitary functioning kidney: do they affect renal outcome? Response
}

\author{
Sebastian Kummer • Jun Oh
}

Received: 20 March 2013 / Accepted: 20 March 2013 / Published online: 10 April 2013

(C) IPNA 2013

To the Editor,

With great interest we read the letter from Dr. Westland and colleagues [1] referring to our review on the influences of gender and gender hormones on kidney diseases [2]. They share interesting data about gender-specific aspects in a Dutch cohort of more than 400 patients with a solitary functioning kidney (SFK).

Taken together, these data of a cohort of congenital anomalies of the kidney and urinary tract (CAKUT) expectedly show a higher prevalence in boys than in girls, which is caused mainly by genetic factors. More detailed statistical analysis could not detect a significant advantage of female gender with regard to secondary disease progression neither pre- nor post-pubertal, at least in a cohort of children and adolescents. However, this may be due to the age of the patient cohort, as Wühl et al. demonstrated that males with CAKUT reached end-stage renal disease earlier than females when patients are followed further into adulthood [3].

In our opinion, the observations presented by Westland et al. [1] are in line with the concept of direct protective estrogenic influences on kidney diseases that was proposed by us and others. In a multitude of acquired

\footnotetext{
S. Kummer $(\square)$

Department of General Pediatrics, Neonatology and Pediatric Cardiology, University Children's Hospital, Moorenstr. 5, 40225 Duesseldorf, Germany

e-mail: sebastian.kummer@med.uni-duesseldorf.de

J. Oh

Pediatric Nephrology, University Medical Center Hamburg-

Eppendorf, Hamburg, Germany
}

kidney diseases, epidemiological research leaves little doubt that female gender is associated with a favorable long-term prognosis in chronic renal diseases. However, while gender-specific incidence in CAKUT is predominantly determined by genetic factors, secondary disease progression may be modified by hormonal influences on kidney structures just as well as in other kidney diseases.

Therefore, we very much appreciate the conclusion of Dr. Westland that a detailed long-term follow-up of wellcharacterized CAKUT cohorts into adulthood will be of great interest to reveal gender-specific factors contributing to stabilization or destabilization of kidney function in these patients.

Conflict of interest statement The authors declare that there is no conflict of interest.

\section{References}

1. Westland R, Schreuder MF (2013) Gender differences in solitary functioning kidney: do they affect renal outcome? Pediatr Nephrol. doi:10.1007/s00467-013-2473-0

2. Kummer S, von Gersdorff G, Kemper MJ, Oh J (2012) The influence of gender and sexual hormones on incidence and outcome of chronic kidney disease. Ped Nephrol 27:12131209

3. Wühl E, van Stralen KJ, Verrina E, Bjerre A, Wanner C, Heaf JG, Zurriaga O, Hoitsma A, Niaudet P, Palsson R, Ravani P, Jager KJ, Schaefer F (2013) Timing and outcome of renal replacement therapy in patients with congenital malformations of the kidney and urinary tract. CJASN 8:67-74 